Proc. Indian Acad. Sci. (Earth Planet. Sci.), Vol. 95, No. 3, November 1986, pp. 427-434.

(C) Printed in India.

\title{
Wind gradients at meteor heights over mid-latitude stations
}

\author{
P C S DEVARA, G CHANDRASEKHAR* and M I AHMED* \\ Indian Institute of Tropical Meteorology, Pune 411 005, India \\ * Department of Physics, Andhra University, Waltair 530 003, India \\ MS received 15 January 1986; revised 30 August 1986
}

\begin{abstract}
The gradients of amplitude and phase of diurnal and semidiurnal components of zonal and meridional winds in the height intervals of $80-90 \mathrm{~km}$ and $90-100 \mathrm{~km}$ are studied using the meteor wind radar data collected at Atlanta $\left(34^{\circ} \mathrm{N}, 84^{\circ} \mathrm{W}\right)$ during the period August 1974-March 1978. The results are compared with those at Adelaide (35'S, $139^{\circ} \mathrm{E}$ ). It is found that the gradients vary in an opposite manner between the two height intervals.
\end{abstract}

Keywords. Meteor winds; amplitude and phase gradients; diurnal and semidiurnal components; mid-latitudes.

\section{Introduction}

Radar tracking of ionized trails of meteors yields accurate and systematic information on upper atmospheric winds in the height region $80-100 \mathrm{~km}$. The use of this method for investigating various phenomena such as turbulence, tides and diffusion in the upper atmosphere at these heights was pioneered by Greenhow and Neufeld $(1956,1959)$ and the results obtained so far at various places in the world have been reviewed by Hocking (1985) and Forbes (1985). Recently, the meteor radar technique has been made more powerful and sophisticated to achieve maximum height resolution of order $1 \mathrm{~km}$ to study the height variation of neutral wind parameters in detail (e.g., Revah et al 1967). Observations carried out at many places indicate that gradients in wind amplitude and phase could be as high as $4 \mathrm{msec}^{-1} \mathrm{~km}^{-1}$ and $12^{\circ} \mathrm{km}^{-1}$ respectively over a height range $85-95 \mathrm{~km}$ (Elford and Robertson 1953; Greenhow and Neufeld 1955). The seasonal and annual variation of wind gradients has been extensively studied by Greenhow and Neufeld (1955, 1956) at Jodrell Bank, England. They report that the magnitude of wind gradient varies between 1.5 and $0.4 \mathrm{msec}^{-1} \mathrm{~km}^{-1}$ during winter and summer months in the height region $85-95 \mathrm{~km}$. In a comparative study between meteor winds and ionospheric drifts, Muller (1968) observed the height gradients of wind amplitude and phase of $1.06 \mathrm{msec}^{-1} \mathrm{~km}^{-1}$ and $4.7^{\circ} \mathrm{km}^{-1}$ respectively. By analyzing the meteor wind data for Adelaide for the period 1967-69, Ahmed and Devara (1979) reported that gradients of amplitude and phase of semidiurnal wind component varied markedly between 80 and $90 \mathrm{~km}$, and 90 and $100 \mathrm{~km}$ height intervals.

An attempt has been made in this paper to study the variation of wind gradients over mid-latitude stations in the altitude range $80-100 \mathrm{~km}$ which contributes the information on propagational characteristics of wave phenomena prevailing at those altitudes. For this purpose, diurnal and semidiurnal components of zonal 
(EW) and meridional (NS) winds between 80 and $100 \mathrm{~km}$ over Atlanta $\left(34^{\circ} \mathrm{N}\right.$, $84^{\circ} \mathrm{W}$ ) obtained using the Georgia Tech radio meteor wind facility during the period August 1974-March 1978 are analysed to obtain information on gradients of amplitude and phase in the height intervals of $80-90 \mathrm{~km}$ and $90-100 \mathrm{~km}$. The results are compared with those at Adelaide $\left(35^{\circ} \mathrm{S}, 139^{\circ} \mathrm{E}\right)$, almost geographically symmetric station. The details of the analysis, results achieved and conclusions drawn are presented below.

\section{Data and analysis}

The data of monthly mean amplitude and phase of diurnal (24 hour) and semidiurnal (12 hour) components of EW and NS winds at 80,90 and $100 \mathrm{~km}$ for Atlanta for the period August 1974-March 1978 are available. The details of the radar facility used and the mathematical procedure followed for estimating the amplitude and phase of diurnal and semidiurnal components from the hourly mean meteor wind values have been described by Roper $(1975,1978)$. The differences in amplitude and in phase were computed between the heights 80 and $90 \mathrm{~km}$, and 90 and $100 \mathrm{~km}$ for diurnal and semidiurnal components of EW and NS winds. The gradients so obtained for each month were averaged for respective months and mean values for all January months, February months etc over the 44-month period (August 1974-March 1978) are utilized for studying the behaviour of wind gradients of amplitude and phase of EW and NS winds in the $80-90 \mathrm{~km}$ and 90-100 km height intervals over a mid-latitude station.

\section{Variation of height gradients over different months}

\subsection{Diurnal amplitude}

The monthly mean variations in the gradients of amplitude of diurnal component of EW and NS winds in the $80-90 \mathrm{~km}$ and $90-100 \mathrm{~km}$ height intervals are shown in figure 1 for Atlanta (A,B,C,D) and Adelaide (a,b,c,d). It is clear from figure 1 that the gradients of EW and NS winds are positive in the $90-100 \mathrm{~km}$ height interval and negative in the $80-90 \mathrm{~km}$ height interval throughout the year at Atlanta. In the case of Adelaide (figure 1a \& b) although the $\mathrm{EW}$ wind gradient in both the height intervals appears to be swinging between positive and negative values, it is negative during most of the months in the $80-90 \mathrm{~km}$ height interval. Also, the variations in the gradients at Atlanta and Adelaide for the height interval $80-90 \mathrm{~km}$ follow each other for most of the months. The results of Atlanta clearly show that the diurnal oscillation is damped (negative amplitude gradient) between the levels 80 and $90 \mathrm{~km}$, and amplified (positive amplitude gradient) between the levels 90 and $100 \mathrm{~km}$.

\subsection{Semidiurnal amplitude}

The monthly mean variations in the gradients of amplitude of semidiurnal component of EW and NS winds in the 80-90 km and 90-100 km height intervals 


$$
\begin{aligned}
& \longmapsto E W\left[v_{1}(100)-v_{1}(90)\right] \\
& 0-\cdots \in W\left[V_{1}(90)-V_{1}(80)\right]
\end{aligned}
$$

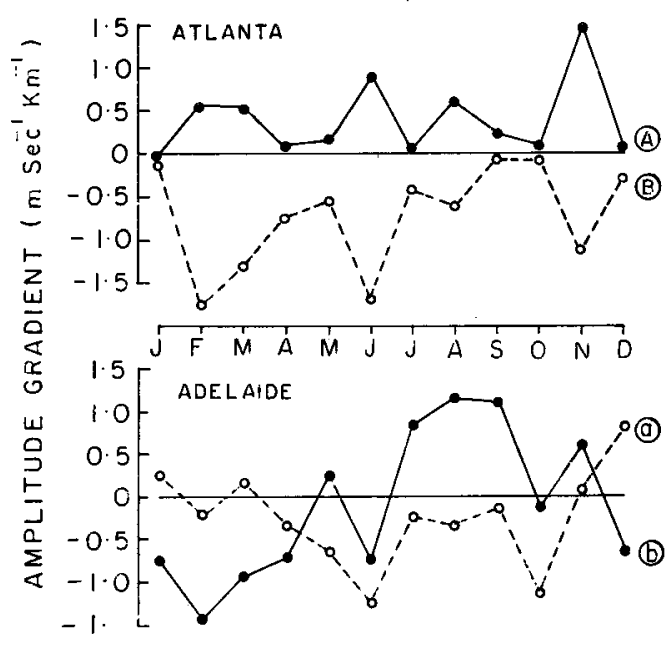

$$
\begin{aligned}
& \longrightarrow N s\left[V_{1}(100)-V_{1}(90)\right] \\
& 0--\infty N S\left[V_{1}(90)-V_{1}(80)\right]
\end{aligned}
$$
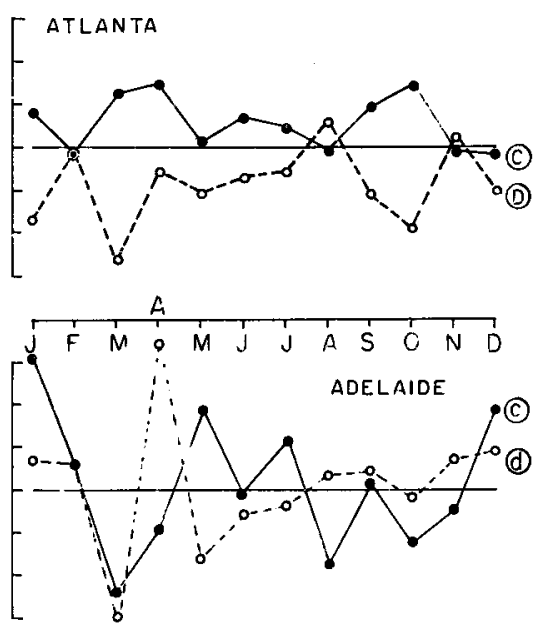

Figure 1. Monthly variations in gradients of amplitude of diurnal component of zonal and meridional winds for Atlanta $(A, B, C, D)$ and Adelaide $(a, b, c, d)$.

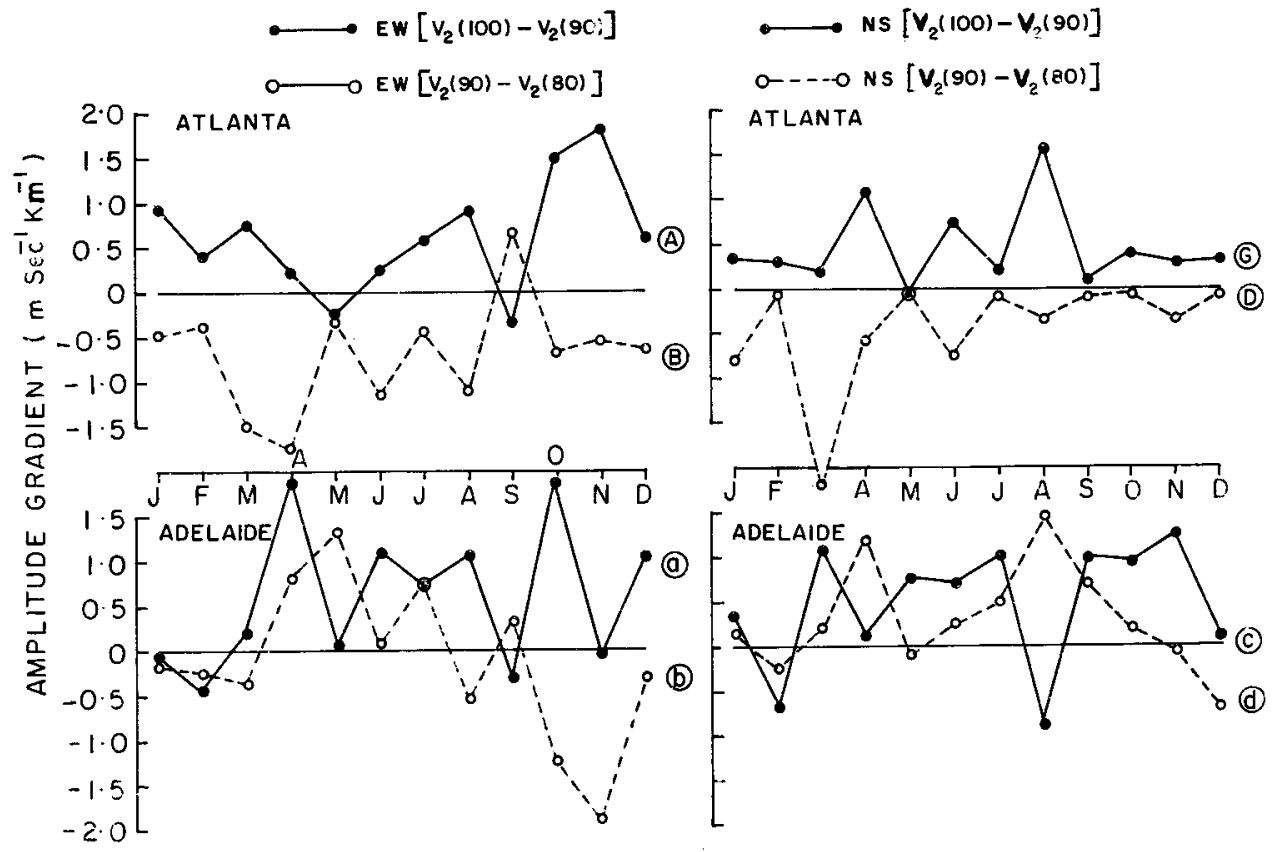

Figure 2. Same as figure 1 for semidiurnal component.

are displayed in figure 2 for Atlanta (A,B,C,D) and Adelaide (a,b,c,d). Figure 2 (A \& a) clearly shows that the gradient of $\mathrm{EW}$ wind is positive in the $90-100 \mathrm{~km}$ height interval throughout the year except during May and September at Atlanta; 
January, February and September at Adelaide. The same gradient is negative in the 80-90 km height interval in all the months except September at Atlanta while it is swinging between positive and negative values at Adelaide. Figure 2 (C \& D) points out that the gradient of semidiurnal component of NS wind at Atlanta is positive in the $90-100 \mathrm{~km}$ height interval and negative in the $80-90 \mathrm{~km}$ height interval throughout the year. At Adelaide, this gradient is positive for both the height intervals except during February and August in the $90-100 \mathrm{~km}$ height interval; February and December in the $80-90 \mathrm{~km}$ height interval.

\subsection{Diurnal phase}

The month-to-month mean variations in the gradients of phase of diurnal component of EW and NS winds in the $80-90 \mathrm{~km}$ and $90-100 \mathrm{~km}$ height intervals are displayed in figure 3 for Atlanta $(A, B, C, D)$ and Adelaide $(a, b, c, d)$. It can be seen that the variations in the gradients of phase of EW and NS winds at Atlanta and Adelaide are erratic and at times follow each other in both the height intervals.

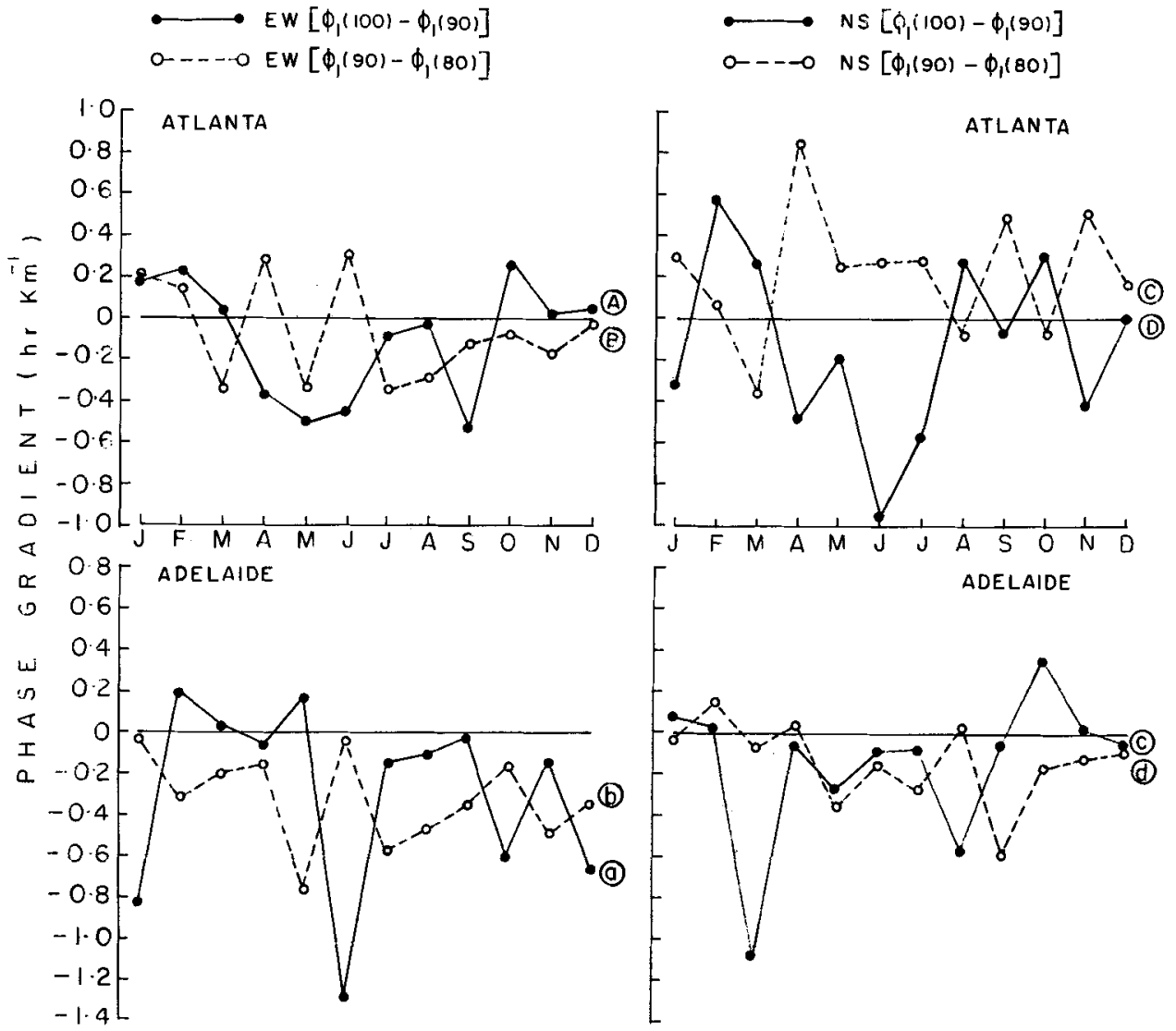

Figure 3. Monthly variations in gradients of phase of diurnal component of zonal and meridional winds for Atlanta (A,B,C,D) and Adelaide (a,b,c,d). 
Also, it is evident from figure $3(a, b, c, d)$ that the nature of variation of gradient in the $80-90 \mathrm{~km}$ interval is almost opposite to that in the $90-100 \mathrm{~km}$ interval.

\subsection{Semidiurnal phase}

Figure 4 depicts the monthly mean variations in the gradients of semidiurnal component of EW and NS winds in the $90-100 \mathrm{~km}$ and $80-90 \mathrm{~km}$ height intervals for Atlanta (A,B,C,D) and Adelaide (a,b,c,d). The magnitudes of gradients at Atlanta are small compared to those at Adelaide. Also, it appears that there is an appreciable change in the gradients of phase for semidiurnal components of $\mathrm{EW}$ and NS winds at Adelaide.

\subsection{Seasonal and annual variation of height gradients}

The seasonal and annual mean gradients of amplitude and phase of diurnal and semidiurnal components of EW and NS winds at Atlanta for the $90-100 \mathrm{~km}$ and $80-90 \mathrm{~km}$ intervals are presented in table 1 . For purposes of comparison, results of
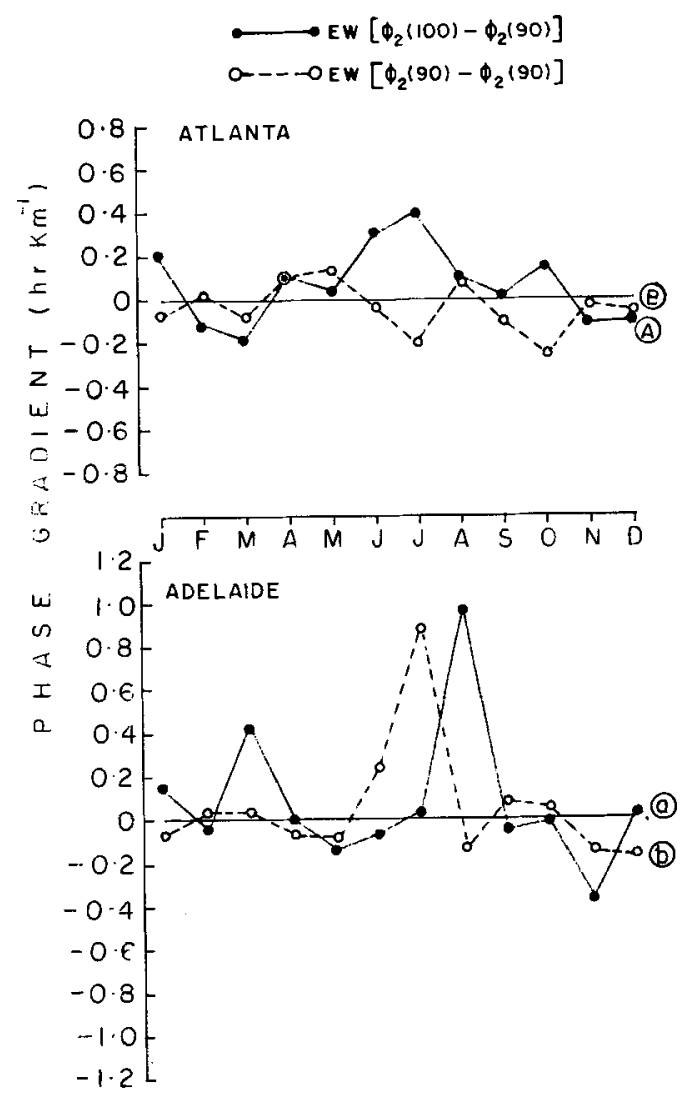

$\longrightarrow N S\left[\Phi_{2}(100)-\Phi_{2}(90)\right]$ $O--O N S\left[\phi_{2}(90)-\phi_{2}(80)\right]$
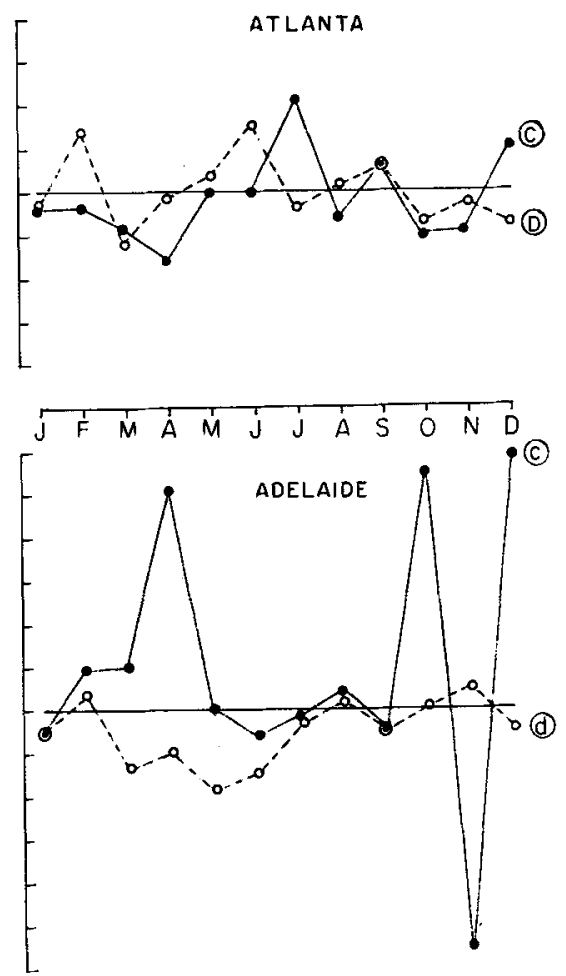

Figure 4. Same as figure 3 for semidiurnal component. 


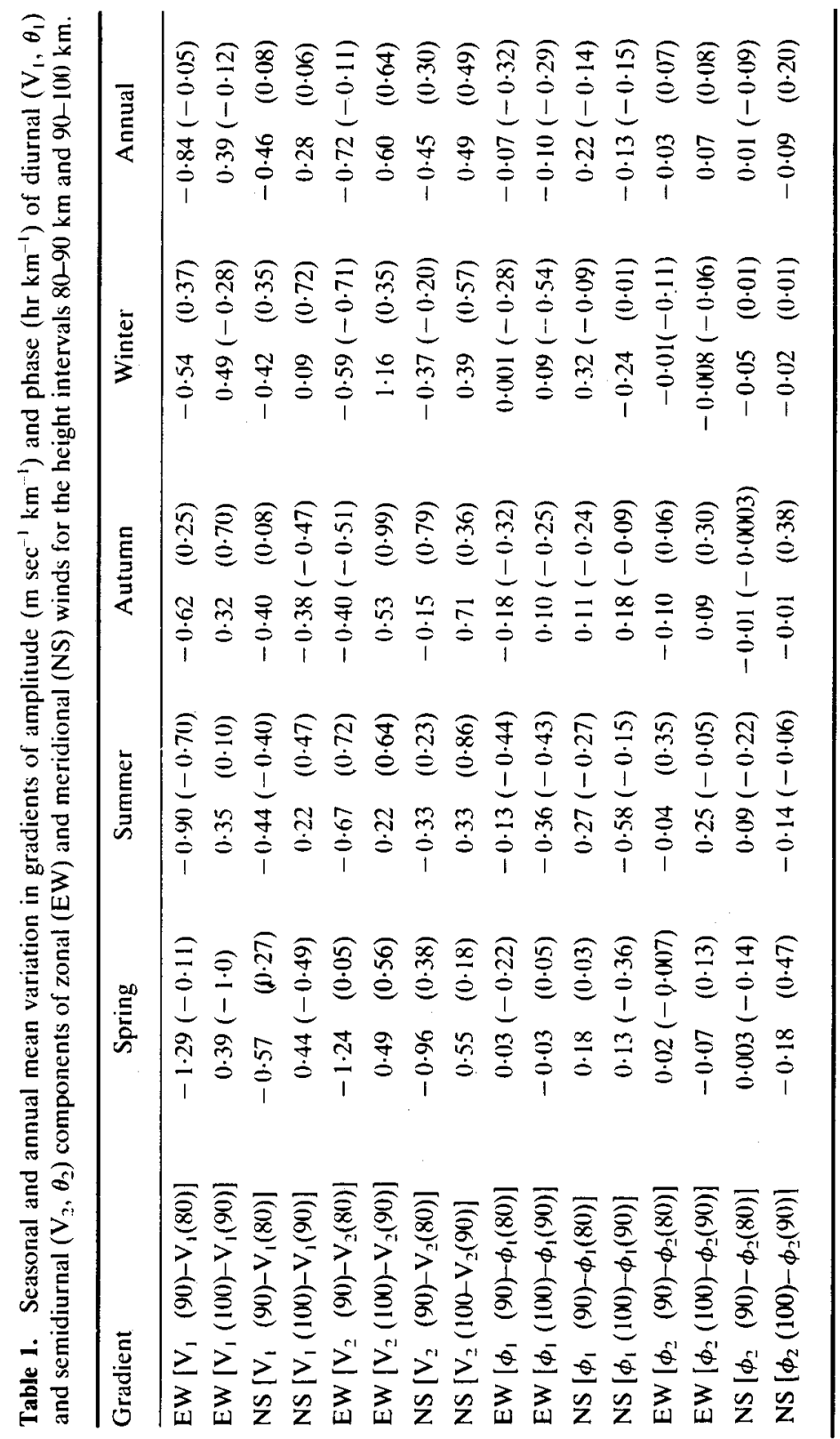


Adelaide (with paranthesis) are also presented in table 1 and the most striking event is that at Atlanta, the seasonal mean height gradients of amplitude and phase of both diurnal and semidiurnal components in the $80-90 \mathrm{~km}$ and $90-100 \mathrm{~km}$ intervals are opposite to each other except for diurnal component of EW wind during summer and winter; semidiurnal components of NS and EW winds during autumn and winter. The annual mean height gradient also showed similar behaviour except for phase of diurnal component of EW wind. Any such systematic variation is not seen at Adelaide.

\section{Discussion}

The variations observed in the height gradients of amplitude and phase of the neutral wind components over the height intervals of $80-90 \mathrm{~km}$ and $90-100 \mathrm{~km}$ are discussed in relation to the atmospheric oscillations. In general, the height variations of wind amplitude and phase at meteor heights can be described by means of the propagational aspects of tidal energy from troposphere to upper atmosphere. The seasonal variations in the height gradients of amplitude and phase observed in the present study are considered to be due to the variations in vertical wavelength and corresponding dominant modes of diurnal and semidiurnal tides over Atlanta and Adelaide as explained by Ahmed and Roper (1983). The opposite trends of variation observed in the gradients of amplitude and phase of diurnal and semidiurnal components of EW and NS winds in the $80-90 \mathrm{~km}$ and $90-100 \mathrm{~km}$ intervals suggest the formation of amplitude node at $90 \mathrm{~km}$ which indicates reflection of tidal energy associated with a phase reversal at $90 \mathrm{~km}$.

\section{Conclusions}

Analysis of the meteor wind data for Atlanta and Adelaide showed that the gradients of amplitude and phase of diurnal and semidiurnal components of EW and NS winds are positive in the $90-100 \mathrm{~km}$ height interval and negative in the 80-90 km height interval at Atlanta whereas at Adelaide they swing between positive and negative values. This suggests that the formation of amplitude node at $90 \mathrm{~km}$ is a more regular feature at Atlanta than at Adelaide, a southern hemisphere station with very nearly the same latitude as that of Atlanta. Inter-comparison of the available mid-latitude meteor wind radar results at closer height intervals may provide further understanding of the problem.

\section{Acknowledgements}

We are grateful to Dr R G Roper, Georgia Institute of Technology, Atlanta, USA for making available to us the meteor wind data for Atlanta and to the reviewers for their comments on the original manuscript. One of us (GC) wishes to thank the University Grants Commission, New Delhi for financial assistance. 


\section{References}

Ahmed M I and Devara P C S 1979 Curr. Sci. 21925

Ahmed M I and Roper R G 1983 J. Atmos. Terr. Phys. 45181

Elford W G and Robertson D S 1953 J. Atmos. Terr. Phys. 4271

Forbes J M 1985 Handbook for Middle Atmosphere Program 16278

Greenhow J S and Neufeld E L 1955 Philos. Mag. 46549

Greenhow J S and Neufeld E L 1956 Philos. Mag. 471157

Greenhow J S and Neufeld E L 1959 Proc. Phys. Soc. London 741

Hocking W K 1985 Handbook for Middle Atmosphere Program 16290

Muller H G 1968 J. Atmos. Terr. Phys. 38701

Revah I, Spizzichino A and Mme. Massebeuf 1967 Note technique GRI/NTA/27 de Centre National d' Etudes des Telecommunications, Ossy-les-Moulineaux, France

Roper R G 1975 Radio Sci. 10363

Roper R G 1978 J. Atmos. Terr. Phys. 8891 